\title{
Prevalence of meeting physical activity guidelines for cancer prevention in Alberta
}

\author{
F. E. Aparicio-Ting, PhD (1,2); C. M. Friedenreich, PhD (1,3,4); K. A. Kopciuk, PhD (1,3,5); R. C. Plotnikoff, PhD (6); \\ H. E. Bryant, PhD $(4,7)$
}

This article has been peer reviewed.

\begin{abstract}
Introduction: Guidelines for recommended physical activity (PA) levels have been developed by the Canadian Society for Exercise Physiology (CSEP) and the U.S. Department of Health and Human Services (USDHHS) for health benefits and by the American Cancer Society (ACS) and the World Cancer Research Fund/American Institute for Cancer Research (WCRF/AICR) for cancer prevention benefits.
\end{abstract}

Methods: We examined if these guidelines were met using a sample of 14294 Albertan participants of the Tomorrow Project, aged 35 to 64 years, enrolled from 2001 to 2005. We used logistic regression to examine correlates of leisure PA behaviour.

Results: An estimated $55 \%, 42 \%, 26 \%$ and $23 \%$ of participants met CSEP, ACS, USDHHS, and WCRF/AICR guidelines, respectively. Women were less likely than men to meet ACS (Odds Ratio [OR] $=0.72,95 \%$ confidence interval $[\mathrm{CI}]: 0.55-0.93$ ), USDHHS (OR $=0.67,95 \%$ CI: 0.50-0.89) and WCRF/AICR (OR $=0.63,95 \%$ CI: 0.47-0.85) guidelines, and being obese was correlated with not meeting USDHHS $(\mathrm{OR}=0.45,95 \% \mathrm{CI}: 0.32-0.65)$ and $\mathrm{WCRF} / \mathrm{AICR}$ guidelines $(\mathrm{OR}=0.79,95 \% \mathrm{CI}$ : $0.63-0.98)$.

Conclusion: Albertans, particularly women and obese individuals, are not sufficiently active for cancer prevention benefits.

Keywords: physical activity, cancer prevention, population health, lifestyle, health behaviour, guidelines

\section{Introduction}

Cancer remains the second leading cause of mortality and morbidity in Canada with an estimated 177800 incident cases and 75000 deaths in 2011. ${ }^{1}$ The total economic cost of cancer has been estimated to represent roughly $9 \%$ of the total cost of illness in Canada. ${ }^{2}$ Whilst treatment and early detection have improved over the past decades, cancer prevention by modifying environmental and lifestyle risk factors remains the most viable long-term strategy for substantially reducing the burden of cancer in Canada. ${ }^{3}$ Several modifiable lifestyle risk factors have been extensively investigated including tobacco use, alcohol use, dietary intake, sun exposure and, more recently, physical activity (PA)., ${ }^{4,5}$
Evidence that PA is a key modifiable lifestyle risk factor that may reduce the risk of several cancers is now accumulating. The risk of colon, breast and endometrial cancers is reduced by $25 \%$ to $30 \%$ in physically active individuals, and evidence for a beneficial effect of PA in reducing prostate, ovarian, lung and other gastrointestinal cancers is emerging. ${ }^{6-9}$ The evidence for a role of PA in cancer etiology is now considered to be fairly strong, consistent and biologically plausible. Several biological mechanisms have been hypothesized to explain how PA reduces cancer risk, including an impact on endogenous sex and metabolic hormone levels, growth factors, inflammation and insulin resistance, all of which impact carcinogenesis. ${ }^{10-12}$ In addition, PA may act to decrease cancer risk by decreasing obesity and central adiposity, both established risk factors for colon, postmenopausal breast, endometrial, kidney and oesophageal cancers. ${ }^{12-14}$ Overweight and obesity result in a shift in the sex and metabolic hormone balance in the body and influence the availability of a number of growth factors involved in the insulin resistance and inflammation pathways that initiate and promote carcinogenesis. ${ }^{14}$ As a result, PA can also be used for weight management to reduce cancer risk. ${ }^{12-14}$

This overwhelming evidence that PA plays an important role in preventing cancer and other chronic diseases has driven the development of PA recommendations or guidelines by a number of organizations.

\section{Author references:}

1. Department of Population Health Research, Alberta Health Services-Cancer Care, Calgary, Alberta, Canada

2. Community Health Sciences, Faculty of Medicine, University of Calgary, Calgary, Alberta, Canada

3. Department of Oncology, Faculty of Medicine, University of Calgary, Calgary, Alberta, Canada

4. Department of Community Health Sciences, Faculty of Medicine, University of Calgary, Calgary, Alberta, Canada

5. Department of Mathematics and Statistics, Faculty of Science, University of Calgary, Calgary, Alberta, Canada

6. School of Education, University of Newcastle, New South Wales, Australia

7. Canadian Partnership Against Cancer, Toronto, Ontario, Canada

Correspondence: Fabiola Aparicio-Ting, Community Health Sciences, Faculty of Medicine, University of Calgary, 3rd Floor, TRW Building, 3280 Hospital Drive N.W., Calgary, AB T2N 4Z6; Tel.: (403) 220-8124; Fax: (403) 270-7307; Email: feaparic@ucalgary.ca 
The purpose of these guidelines is to encourage inactive populations to engage in PA and to provide a target to set personal PA goals and measure progress..$^{15}$ In Canada, the Canadian Society for Exercise Physiology (CSEP) has developed guidelines for adults, older adults and children. ${ }^{16}$ The 2003 CSEP guidelines recommend that adults engage in at least 150 minutes of moderate to vigorous aerobic PA per week. The guidelines also indicate that more PA provides greater health benefits. ${ }^{16}$ Moderate-intensity activity is defined as aerobic activity that is not exhausting and leads to light perspiration (e.g. brisk walking), while vigorous activity results in rapid heart rates, sweating and heavy breathing (e.g. jogging, aerobics). ${ }^{17-18}$ CSEP also recommends that adults incorporate strength training activities at least two days per week; however, our study focuses only on levels of aerobic activity.

The American Cancer Society (ACS), ${ }^{19}$ the United States Department of Health and Human Services (USDHHS) with the United States Department of Agriculture, ${ }^{20}$ and the World Cancer Research Fund with the American Institute for Cancer Research (WCRF/AICR) ${ }^{21}$ also recommend a minimum of 150 minutes of moderate to vigorous PA per week for general health. Further, they have extended their recommendations to include higher levels of activity to prevent other chronic diseases. Based on reviews of current research, ACS recommended at least 45 minutes of moderate and preferably vigorous PA at least 5 days per week to reduce cancer risk. USDHHS recommended that adults engage in at least 30 minutes of moderate-intensity PA on most days of the week as a means of reducing the risk of chronic diseases. However, USDHHS also recommended that adults engage in 60 minutes of moderate to vigorous activity on most days of the week to help manage body weight and prevent weight gain, and 60 to 90 minutes of daily moderate to vigorous activity for sustained weight loss to reduce the risk of chronic disease, including cancer, associated with overweight and obesity. ${ }^{20}$ Most recently, WCRF/AICR conducted a comprehensive review of current evidence and recommended that adults aim to participate in at least 60 minutes of moderate activity or 30 minutes or more of vigorous activity daily as a means of reducing cancer risk. ${ }^{21}$
Using data from the Alberta cohort study known as the Tomorrow Project, ${ }^{22}$ our aim was to estimate the percentage of Albertans meeting the PA guidelines for cancer prevention. Since there has been little research on the levels of PA necessary for cancer prevention, this study also explored potential associations between personal and demographic characteristics and meeting PA guidelines for cancer prevention.

\section{Methods}

\section{Study sample}

The Population Research Laboratory at the University of Alberta recruited Tomorrow Project participants from all geographic regions of Alberta using the Random Digit Dialing (RDD) method. ${ }^{23}$ This method was selected for random population sampling because $97 \%$ of Alberta households had at least one telephone line in 2000. ${ }^{24}$ Participants were sampled from over 400 cities, towns and villages and from all rural areas throughout the province to build a geographically representative sample. ${ }^{22}$

A total of 29270 Albertans aged 35 to 65 years were recruited to the Tomorrow Project from 2001 to 2005 , or $49 \%$ of the 59735 eligible individuals who responded positively to telephone calls; the number of eligible individuals who did not respond to telephone calls is unknown, so the response rate cannot be calculated. Of the 29270 people recruited, 16040 had complete data for lifestyle risk factors. A total of 1746 participants were excluded from this study sample based on the established exclusion criteria: transgendered $(n=2)$, over 65 years old $(n=1328)$, pregnant ( $\mathrm{n}=55)$, prior cancer diagnosis $(\mathrm{n}=188)$, not resident in Alberta ( $\mathrm{n}=75)$, and being underweight ( $\mathrm{n}=98$ ). Data for the remaining 14294 Tomorrow Project participants were used for this analysis. We can conclude that the response rate cannot be greater than 25\% (14 294/[59 $735-1746])$.

This study received approval by the ethics review boards of the University of Calgary and the former Alberta Cancer Board, now part of Alberta Health Services-Alberta Cancer Research Ethics Committee.

\section{Data collection}

Albertans who consented to participate in the Tomorrow Project completed the selfadministered, mailed questionnaires about lifestyle risk factors and exposures. Data collected using the Past Year Total Physical Activity Questionnaire (PYTPAQ) and the Health and Lifestyle Questionnaire (HLQ) were analyzed in this study. The PYTPAQ is a valid and reliable self-administered questionnaire used to collect the frequency, duration and intensity of occupational, household, active transport and leisure activities of the previous twelve months. ${ }^{25}$ The PYTPAQ was correlated with 7-day activity logs (Spearman rank correlation $[\rho]=0.41$ ) and 7-day accelerometer measurements $(\rho=0.26)$. The HLQ was developed from pre-existing questionnaires, including those used in the Canadian Community Health Survey (CCHS) cycle $1.1{ }^{26}$ the Prostate, Lung, Colorectal and Ovarian Cancer Screening Trial, ${ }^{27}$ and the European Prospective Investigation into Cancer and Nutrition ${ }^{28}$ to assess health history, family history, cancer screening practices, smoking, stress, social support and demographic characteristics.

Participating in sufficient leisure activity to meet the PA guidelines recommended by CSEP, ACS, USDHHS and WCRF/AICR was the outcome of interest for this study. While occupational, household and transportation activities can also contribute to overall health, leisure activity is the most modifiable type of activity and has been the main target of public health promotion of PA. ${ }^{15,19,21}$ Four outcome variables were derived from data collected using the PYTPAQ. Metabolic Equivalents (MET) values, the ratio of energy expenditure of an activity to the energy cost of the metabolic rate at rest, ${ }^{18}$ were assigned to each reported leisure, household, occupational and active transport activity using the Compendium of Physical Activities. ${ }^{29}$ Reported values for frequency and duration for each separate activity with intensity of 3 or more METs (considered a moderate intensity) were multiplied for a single estimate of the hours per week at moderate and vigorous intensity. Outcome variables were derived as follows:

- To meet the CSEP guidelines of at least 2.5 hours/week of moderate to vigorous activity; 
- To meet the ACS guidelines of at least 3.75 hours/week of moderate to vigorous activity;

- To meet the WCRF/AICR guidelines of at least 7 hours/week of moderateintensity activity or 3.5 hours/week of vigorous activity;

- To meet the USDHHS guidelines of at least 5 hours/week of moderate to vigorous activity to prevent weight gain.

Pertinent explanatory variables obtained from the HLQ included age, sex, annual household income, educational attainment, marital status, employment status, pre-existing chronic conditions (including hypertension, hypercholesterolemia and diabetes), self-rated health status, smoking behaviour, social support (using the Medical Outcomes Study Social Support Survey) $)^{30}$ and urban or rural residence (from postal codes).

\section{Statistical analysis}

Univariate analysis provided an overall description of the study sample and an estimate of the percentage of the study sample that met each of the PA guidelines. We used the Cochran-Armitage test to assess trends across proportions that met each guideline.

Characteristics of the study sample and of the Alberta population, using 2001 Canadian census data, ${ }^{31}$ were compared to assess the representativeness of the sample. Prevalence of smoking and weight status were obtained from the CCHS 2.1. The CCHS 2.1 had a response rate of about $83 \%$ in Alberta in 2003 and reflects population-based estimates of health. ${ }^{32} \mathrm{~A}$ postal code conversion file from Statistics Canada was used to code participants into health regions. Sample weights were estimated using the distribution weights of age group and sex by health region of residence as well as by educational attainment and annual household income according to Canadian 2001 census data. The proportion of the sample that met each guideline was then weighted to obtain estimates of the percentage of Albertans that met each of the guidelines.
Logistic regression was used to explore the potential correlates of meeting each guideline. Prior to modelling, the data were assessed for multicollinearity. ${ }^{33}$ Variable selection was done through hierarchical backward elimination, ${ }^{34}$ beginning with all available explanatory variables and all models adjusted for age, sex and BMI. A 10-fold cross-validation procedure was used to avoid overfitting. ${ }^{35}$ For each guideline, data were divided into 10 randomly selected subsets and variable selection was conducted using each of 9 training sets. The resulting model was fit to a test subset, repeating this procedure 10-fold until each subset was used as a test subset. ${ }^{35}$ Variables selected in at least 3 of 10 folds at a significance level of $p=.05$, were included in the final models. Estimated coefficients and their standard errors were averaged across the folds and used to yield odds ratio (OR) estimates and $95 \%$ confidence intervals (CIs). Final models were fit to the entire sample and tested for goodnessof-fit using the Hosmer-Lemeshow test, for predictive value using receiver operating characteristic (ROC) curves, and for appropriateness of the logit link. ${ }^{36}$ All statistical procedures were performed using STATA version 10 (StataCorp LP). ${ }^{37}$

\section{Results}

\section{Study sample characteristics}

The study sample was largely female (60\%) and averaged 49 years of age (Table 1). Most participants were of high socio-economic status, with one-third having some university education or higher (33\%) and an annual household income of $\$ 80,000$ or higher $(37 \%)$. Most were married or living with a common-law partner $(77 \%)$, employed $(77.5 \%)$ and urban residents $(80 \%)$. Most of the sample self-rated their health as very good or better (61\%), yet the majority were overweight (39\%) and obese (25\%) (Table 1). In comparison to the Alberta population, the study participants were more likely to be female, older, more educated and wealthier (Table 2). Study participants were also more likely to be overweight and obese and less likely to smoke than the Alberta population (Table 2). Overall, the sample represented all nine former health regions in Alberta.

\section{Meeting physical activity guidelines}

Those who met CSEP and ACS guidelines (63\% and $48 \%$, respectively) mainly participated in leisure activities rather than in household, occupational or active transport activities (Table 3). On the other hand, participants were most likely to meet USDHHS and WCRF/AICR guidelines through occupational activity. Regardless of the type of activity considered, participants were most likely to meet CSEP guidelines (93\%) and least likely to meet USDHHS and WCRF/AICR guidelines (78\% and $72 \%$, respectively) (Table 3 ).

\section{Prevalence of meeting physical activity guidelines in Alberta}

After weighting by age, sex, and health region of residence and then by educational attainment and household income, $55 \%$ of the overall Alberta population was estimated to be sufficiently active to meet CSEP guidelines for general good health. However, the proportions of Albertans estimated to meet the more rigorous guidelines set by ACS, USDHHS and WCRF/AICR were comparatively low: $42 \%, 26 \%$ and $23 \%$, respectively (Figure 1).

\section{Correlates of meeting physical activity guidelines through leisure activity}

Overall, marital status, employment status, annual household income and self-rated health status were correlated with meeting all PA guidelines through leisure activity (Table 4). Divorced, separated or widowed participants were more likely to meet CSEP $(\mathrm{OR}=1.54 ; 95 \% \mathrm{CI}: 1.06-2.26)$, ACS $(\mathrm{OR}=1.63 ; 95 \% \mathrm{CI}: 1.12-2.35)$, USDHHS $(\mathrm{OR}=1.62 ; 95 \% \mathrm{CI}: 1.08-2.43)$, and WCRF/AICR (OR $=1.51$; 95\% CI: 1.09-2.10) guidelines than those who were married or single. Retired participants were also more likely to meet all guidelines than those who were employed or unemployed. However, this strength of association increased with increasingly demanding guidelines: retirees were almost 3 times more likely to meet WCRF/AICR guidelines $(\mathrm{OR}=2.76$; $95 \% \mathrm{CI}$ : $1.57-4.87$ ) compared to over 2 times more likely to meet CSEP guidelines (OR $=2.30 ; 95 \%$ CI: 1.32-4.01). In contrast, the strength of 
TABLE 1

Study sample characteristics, Alberta, 2005

\begin{tabular}{|c|c|c|c|}
\hline Variable & $\begin{array}{c}\text { Whole sample } \\
\text { n= } 14294 \\
\%\end{array}$ & $\begin{array}{c}\text { Men } \\
\mathbf{n}=5729 \\
\%\end{array}$ & $\begin{array}{c}\text { Women } \\
\mathbf{n}=\mathbf{8 5 6 5} \\
\%\end{array}$ \\
\hline Mean age (SD), years $(n=13970)$ & $48.7(7.9)$ & $48.6(7.9)$ & $48.7(8.0)$ \\
\hline \multicolumn{4}{|l|}{ BMI, \% (n =13 970) } \\
\hline $18.5-24.9 \mathrm{~kg} / \mathrm{m}^{2}$ & 35.4 & 24.6 & 42.7 \\
\hline $25.0-29.9 \mathrm{~kg} / \mathrm{m}^{2}$ & 39.4 & 49.3 & 32.7 \\
\hline $30.0-39.9 \mathrm{~kg} / \mathrm{m}^{2}$ & 22.5 & 24.7 & 21.0 \\
\hline$\geq 40 \mathrm{~kg} / \mathrm{m}^{2}$ & 2.7 & 1.5 & 3.5 \\
\hline \multicolumn{4}{|l|}{ Marital status, $\%(n=14216)$} \\
\hline Married/Common law & 76.9 & 81.9 & 75.4 \\
\hline Divorced, separated or widowed & 15.2 & 10.7 & 18.5 \\
\hline Single & 6.5 & 7.3 & 6.1 \\
\hline \multicolumn{4}{|l|}{ Educational attainment, \% $(n=14005)$} \\
\hline Some high school & 8.6 & 8.9 & 8.4 \\
\hline High school diploma & 18.6 & 15.0 & 21.0 \\
\hline Technical school/College training & 39.9 & 40.7 & 39.3 \\
\hline Some university/University degree & 22.9 & 22.7 & 22.9 \\
\hline Postgraduate university & 10.1 & 12.6 & 8.4 \\
\hline \multicolumn{4}{|l|}{ Employment status, $\%(n=14051)$} \\
\hline Employed full-time & 60.7 & 80.6 & 47.4 \\
\hline Employed part-time & 16.8 & 5.6 & 24.2 \\
\hline Unemployed & 13.5 & 5.0 & 19.1 \\
\hline Retired & 8.0 & 7.2 & 8.5 \\
\hline Self-employed & 1.0 & 1.4 & 0.8 \\
\hline \multicolumn{4}{|c|}{ Annual household income, $\%(n=14$ 022) } \\
\hline$<\$ 20,000$ & 6.0 & 3.6 & 7.5 \\
\hline$\$ 20,000-\$ 39,999$ & 16.6 & 12.1 & 19.6 \\
\hline$\$ 40,000-\$ 59,999$ & 20.0 & 19.3 & 20.4 \\
\hline$\$ 60,000-\$ 79,999$ & 20.1 & 21.6 & 19.1 \\
\hline$\$ 80,000-\$ 99,999$ & 14.5 & 16.0 & 13.4 \\
\hline$\geq \$ 100,000$ & 22.9 & 27.3 & 19.9 \\
\hline \multicolumn{4}{|l|}{ Place of residence, $\%(n=14$ 294) } \\
\hline Rural & 19.6 & 19.9 & 20.0 \\
\hline Urban & 80.4 & 80.1 & 80.0 \\
\hline \multicolumn{4}{|l|}{ Self-rated health status, $\%(n=14036)$} \\
\hline Excellent & 17.3 & 15.8 & 18.3 \\
\hline Very Good & 43.4 & 43.2 & 43.6 \\
\hline Good & 33.4 & 35.3 & 32.1 \\
\hline Fair & 5.3 & 5.2 & 5.3 \\
\hline Poor & 0.6 & 0.4 & 0.7 \\
\hline \multicolumn{4}{|l|}{ Current smoking status, $\%(n=14$ 151) } \\
\hline Non-smoker & 80.5 & 79.8 & 80.9 \\
\hline Occasional & 3.5 & 3.8 & 3.2 \\
\hline Daily & 16.0 & 16.4 & 15.8 \\
\hline \multicolumn{4}{|l|}{ Hypertension, \% ( $n=14$ 031) } \\
\hline Yes & 19.5 & 21.7 & 18.0 \\
\hline \multicolumn{4}{|l|}{ Hypercholesterolemia, \% $(n=14$ 022) } \\
\hline Yes & 24.8 & 29.8 & 21.4 \\
\hline \multicolumn{4}{|l|}{ Diabetes, \% ( $\mathrm{n}=14$ 237) } \\
\hline Yes & 3.8 & 4.5 & 3.3 \\
\hline
\end{tabular}

Abbreviations: BMI, body mass index; SD, standard deviation. association between an annual household income of $\$ 100,000$ or higher and meeting CSEP guidelines (OR $=2.51 ; 95 \% \mathrm{CI}$ : 1.36-4.63) was higher than for meeting WCRF/AICR guidelines (OR $=1.56$; 95\% CI: 1.06-3.27). Participants who rated their health as good or worse were significantly less likely to meet CSEP guidelines $(\mathrm{OR}=0.54,95 \% \mathrm{CI}: 0.37-0.80)$, whereas participants with self-rated health status lower than excellent were significantly less likely to meet ACS (OR $=0.72$; $95 \%$ CI: 0.52-0.99), USDHHS (OR = 0.72 ; $95 \%$ CI: 0.53-0.97) and WCRF/AICR $(\mathrm{OR}=0.67 ; 95 \% \mathrm{CI}: 0.47-0.95)$ guidelines (Table 4).

Sex and BMI were the only characteristics found to be significantly associated with sufficient activity to meet guidelines relevant for cancer prevention (Table 4). Women were less likely than men to meet guidelines recommended by ACS $(\mathrm{OR}=0.72 ; 95 \% \quad \mathrm{CI}: \quad 0.55-0.93)$, USDHHS (OR $=0.67 ; 95 \% \mathrm{CI}: 0.50-0.89$ ) or WCRF/AICR (OR $=0.63 ; 95 \% \mathrm{CI}$ : $0.47-0.85$ ), though there were no sex differences in meeting CSEP guidelines for general health. Being overweight was associated only with meeting USDHHS guidelines (OR $=0.52 ; 95 \%$ CI: 0.39-0.70), whereas being obese was associated with meeting both USDHHS $(\mathrm{OR}=0.45 ; 95 \% \mathrm{CI}: 0.32-0.65)$ and WCRF/IARC guidelines (OR $=0.79 ; 95 \%$ CI: 0.63-0.98).

\section{Discussion}

Our findings suggest that few Albertans are participating in sufficient leisure activity to reduce cancer risk, probably because of the higher levels of activity required to meet ACS or WCRF/AICR guidelines compared to CSEP guidelines for general health. Since the WCRF/AICR guidelines take almost 3 times as long as do the CSEP guidelines, participants need to commit more time to physical activity to benefit from cancer risk reduction. Thus, retired people, with more available leisure time, were more likely to be active at levels recommended for cancer prevention.

These findings are consistent with the Health Belief Model, which proposes that as perceived barriers for a behaviour 
TABLE 2

Comparison of sociodemographic characteristics between the study sample (2005) and the Alberta population (2001 Canadian Census data)

\begin{tabular}{|c|c|c|}
\hline Sociodemographic characteristics & Study sample (\%) & Alberta $(\%)^{\mathrm{a}}$ \\
\hline \multicolumn{3}{|l|}{ Age range, years } \\
\hline $35-39$ & 16.6 & 21.4 \\
\hline $40-44$ & 20.6 & 22.5 \\
\hline $45-49$ & 20.3 & 19.7 \\
\hline $50-54$ & 17.7 & 16.0 \\
\hline $55-59$ & 14.3 & 11.5 \\
\hline $60-64$ & 10.4 & 9.0 \\
\hline \multicolumn{3}{|l|}{ Sex } \\
\hline Men & 40.1 & 50.3 \\
\hline Women & 59.9 & 49.7 \\
\hline \multicolumn{3}{|l|}{$\mathrm{BMI}^{\mathrm{b}}$} \\
\hline $18.5-24.9 \mathrm{~kg} / \mathrm{m}^{2}$ & 35.4 & 43.5 \\
\hline $25.0-29.9 \mathrm{~kg} / \mathrm{m}^{2}$ & 39.4 & 38.1 \\
\hline$\geq 30 \mathrm{~kg} / \mathrm{m}^{2}$ & 25.2 & 18.4 \\
\hline \multicolumn{3}{|l|}{ Current smoking status ${ }^{\mathrm{b}}$} \\
\hline Daily smoker & 16.0 & 24.5 \\
\hline \multicolumn{3}{|l|}{ Educational attainment } \\
\hline Some high school & 8.6 & 22.3 \\
\hline High school diploma & 18.6 & 16.0 \\
\hline Technical school/College training & 39.9 & 29.1 \\
\hline Some university/University degree & 22.9 & 27.4 \\
\hline Postgraduate university & 10.1 & 5.1 \\
\hline \multicolumn{3}{|l|}{ Annual household income } \\
\hline$<\$ 20,000$ & 5.8 & 32.6 \\
\hline$\$ 20,000-\$ 39,999$ & 16.2 & 29.3 \\
\hline$\$ 40,000-\$ 59,999$ & 19.5 & 19.3 \\
\hline$\$ 60,000-\$ 74,999$ & 19.7 & 8.2 \\
\hline$\geq \$ 75,000$ & 36.6 & 10.5 \\
\hline
\end{tabular}

${ }^{a}$ Data from 2001 Canada Census. ${ }^{31}$

${ }^{\mathrm{b}}$ Data from Canadian Community Health Survey Cycle 2.1 (2003) ${ }^{32}$ increase, the likelihood of performing the health behaviour decreases. ${ }^{38}$ Sufficient leisure activity to reduce cancer risk is likely associated with greater barriers related to time, competing commitments, and motivation than participating in the lower levels required for general health benefits. In addition, CSEP guidelines have been consistently communicated to Canadians since $1998 .{ }^{15}$ Canadians who aim to be active may be striving to meet CSEP guidelines for general health benefits without being aware that higher levels of activity are needed to reduce cancer risk. Perceived benefits, another component of the Health Belief Model, are also important to encourage behaviour; 38 increasing public awareness of the PA guidelines relevant to preventing cancer may encourage individuals to use these guidelines as a benchmark for being physically active.

In our study, women were less likely than men to participate in the levels of leisure activity recommended for cancer risk reduction, a finding consistent with other reports, ${ }^{39-41}$ even after controlling for other sociodemographic factors. A number of cultural and social contextual factors, such as gender roles, result in differences in PA behaviour between men and women. ${ }^{40-44}$ Motivating factors are also different; women more commonly report body image, appearance and health concerns as being equally important reasons for being physically active. ${ }^{45-48}$ These results

TABLE 3

Percentage of study population that met physical activity guidelines by organization and type of physical activity, Alberta, 2001-2005

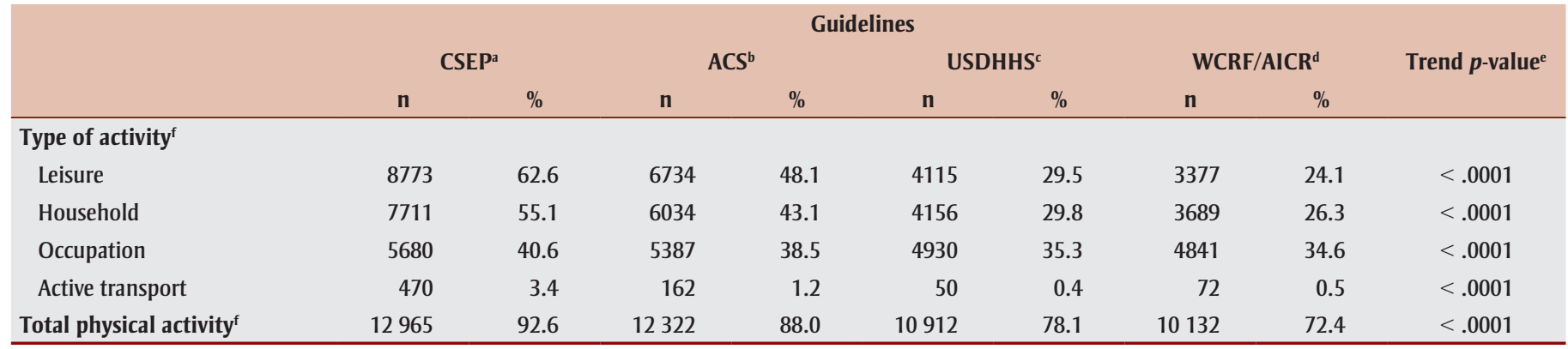

Abbreviations: ACS, American Cancer Society; AICR, American Institute for Cancer Research; CSEP, Canadian Society for Exercise Physiology; PA, physical activity;

USDHHS, United States Department of Health and Human Services; WCRF, World Cancer Research Fund.

${ }^{\text {a }}$ Minimum 2.5 hours/week of moderate to vigorous PA.

${ }^{b}$ Minimum 3.75 hours/week of moderate to vigorous PA.

${ }^{c}$ Minimum 5 hours/week of moderate to vigorous PA to prevent weight gain.

${ }^{\mathrm{d}}$ Minimum 7 hours/week of moderate-intensity PA or 3.5 hours/week of vigorous PA.

e Cochran-Armitage test for trend.

${ }^{f}$ Moderate- and vigorous-intensity activity. 
FIGURE 1

Estimated $^{\mathrm{a}}$ Alberta population percentage that met physical activity guidelines through leisure activity, 2001-2005

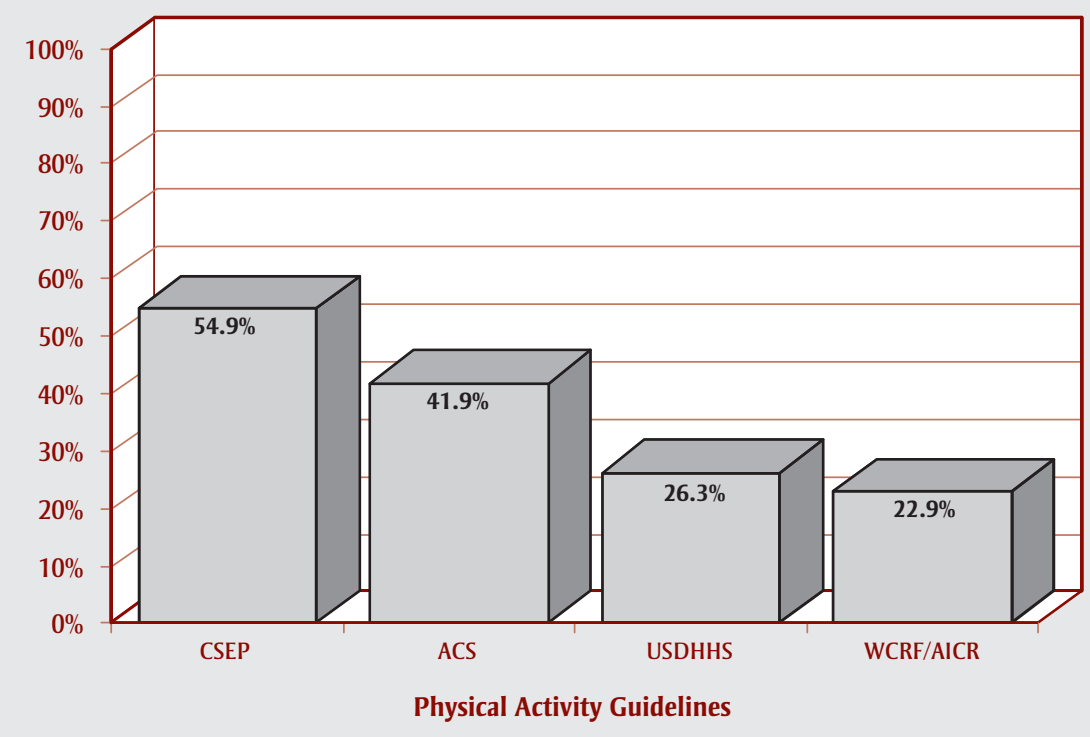

Abbreviations: ACS, American Cancer Society; AICR, American Institute for Cancer Research;

CSEP, Canadian Society for Exercise Physiology; USDHHS, United States Department of Health and Human Services; WCRF, World Cancer Research Fund.

${ }^{\text {a }}$ Weighted by health region of residence, age and sex, and further weighted by household income and educational attainment using 2001 Census data.

suggest that gender differences need to be considered when prompting PA for cancer prevention in the population.

Despite gender differences, both men and women who were either overweight or obese were significantly less likely than normal weight individuals to meet USDHHS and WCRF/AICR guidelines. Given that these guidelines require 30 to 60 minutes of daily leisure PA, it is possible that overweight and obese individuals may be physically unable to take part in sufficient amounts of activity or make the lifestyle changes required to achieve these levels of activity. In fact, overweight and obese individuals are less likely than normal weight adults to adhere to PA programs, even those that involve only walking. ${ }^{49-50}$ PA may be especially challenging for those overweight and obese individuals with pain or discomfort exacerbated by their weight status. ${ }^{51}$ Alternatively, these results may reflect the fact that sufficient activity to meet USDHHS and WCRF/AICR guidelines aids in weight loss and protects from unhealthy weight. ${ }^{52-55}$ Either way, our results are consistent with other findings that overweight and obesity are independently associated with low levels of PA. ${ }^{51,56-57}$
Individuals in the highest income category were the most likely to participate in sufficient activity to meet all guidelines, also consistent with previous findings. ${ }^{42,58-59}$ Low socio-economic status is often associated with caregiver responsibilities, time devoted to childcare, physical labour as an occupation, lack of transportation, unsafe neighbourhoods, inflexible work schedules and transient homes, ${ }^{41}$ all of which may hamper participation in leisure activity. Interestingly, the association between annual household income and meeting PA guidelines decreased in strength as the amount of activity needed to meet guidelines increased. This relation was weakest for meeting USDHHS and WCRF/AICR guidelines, suggesting that participation in high levels of leisure PA may be moderated by more complex intrapersonal factors. The weakening association between activity and income may also reflect that retirees were more frequently middle-class income earners, yet more likely to meet guidelines for cancer risk reduction. Despite this weaker relation, income was still strongly correlated with meeting guidelines for cancer prevention.
This study is among the first to investigate the prevalence of PA at levels sufficient for cancer prevention. So far, estimates of PA among Canadians have used the CSEP guidelines as the benchmark for sufficient activity for health benefits. Using this approach, the CCHS (cycle 2.1) estimated that during the time period of this study, $48 \%$ of Canadians ${ }^{60}$ and $52 \%$ of Albertans, ${ }^{61}$ 35 to 65 years old, were physically active. ${ }^{61}$ In comparison, our current study estimated that $63 \%$ of Albertans were sufficiently active to meet CSEP guidelines (Table 3 ). This difference in estimates persisted even when the estimate was adjusted for age, sex, income and educational attainment, suggesting that the study sample differs from the Alberta population in other factors that need to be adjusted for when estimating population prevalence for PA, which is a complex behaviour. The higher estimate derived from our study could also be attributed to a "healthy enrolee" effect. About $60 \%$ of the study sample rated their health as very good or excellent, and the study sample had a lower prevalence of diabetes $3.8 \%$ compared to $4.9 \%$ for Albertans ${ }^{61}$ ) and smoking than the Alberta population (16\% of the study sample were daily smokers versus $25 \%$ of Albertans). Despite being more likely to be overweight and obese, study participants appeared to be healthier than Albertans as a whole and may have been more likely to participate in leisure PA. Differences in leisure PA measurement between the CCHS and the PYTPAQ used in our study may also account for the difference in prevalence estimates. The CCHS utilized a multi-part item to report frequency and duration of participation in a given list of leisure activities over the past three months. ${ }^{62}$ In contrast, the PYTPAQ assessed leisure activity over the past year using a more detailed approach that permitted participants to report duration, frequency and intensity of all recreational and sports activities. The PYTPAQ was more likely to reflect usual activity patterns, while the short time frame of the CCHS questionnaire may be more influenced by seasonal variation and acute illness. ${ }^{63}$

During the study period, $45.9 \%$ of U.S. adults $^{64}$ and $29 \%$ of European Union adults from 15 countries $^{65}$ were estimated to participate in 150 minutes of moderate 
TABLE 4

Estimated odds ratios ${ }^{\mathrm{a}}$ for meeting physical activity guidelines through leisure activity, Alberta, 2001-2005

\begin{tabular}{|c|c|c|c|c|c|c|c|c|}
\hline \multirow{2}{*}{$\begin{array}{l}\text { Variable } \\
\text { Age, years }\end{array}$} & \multicolumn{8}{|c|}{ Guidelines } \\
\hline & \multicolumn{2}{|c|}{$\begin{array}{c}\text { CSEPb } \\
\text { OR }(95 \% \mathrm{CI})\end{array}$} & \multicolumn{2}{|c|}{$\begin{array}{c}\text { ACSc } \\
\text { OR }(95 \% \mathrm{Cl})\end{array}$} & \multicolumn{2}{|c|}{$\begin{array}{l}\text { USDHHS }^{d} \\
\text { OR }(95 \% \mathrm{CI})\end{array}$} & \multicolumn{2}{|c|}{$\begin{array}{l}\text { WCRF/AICR } \\
\text { OR }(95 \% \mathrm{CI})\end{array}$} \\
\hline $35-39$ & 1.00 & & 1.00 & & 1.00 & & 1.00 & \\
\hline $40-44$ & 1.02 & $(0.69,1.51)$ & 0.99 & $(0.68,1.44)$ & 0.94 & $(0.63,1.41)$ & 0.91 & $(0.60,1.39)$ \\
\hline $45-49$ & 0.98 & $(0.66,1.44)$ & 0.98 & $(0.68,1.43)$ & 0.91 & $(0.61,1.37)$ & 0.87 & $(0.57,1.34)$ \\
\hline $50-54$ & 0.81 & $(0.54,1.22)$ & 0.86 & $(0.58,1.27)$ & 0.86 & $(0.56,1.32)$ & 0.82 & $(0.53,1.29)$ \\
\hline $55-59$ & 0.80 & $(0.52,1.25)$ & 0.80 & $(0.52,1.24)$ & 0.74 & $(0.46,1.21)$ & 0.75 & $(0.45,1.24)$ \\
\hline $60-65$ & 0.75 & $(0.44,1.28)$ & 0.72 & $(0.42,1.22)$ & 0.72 & $(0.40,1.29)$ & 0.67 & $(0.36,1.24)$ \\
\hline \multicolumn{9}{|l|}{ Sex } \\
\hline Male & 1.00 & & 1.00 & & 1.00 & & 1.00 & \\
\hline Female & 0.85 & $(0.65,1.11)$ & 0.72 & $(0.55,0.93)$ & 0.67 & $(0.50,0.89)$ & 0.63 & $(0.47,0.85)$ \\
\hline \multicolumn{9}{|l|}{$\mathrm{BMI}, \mathrm{kg} / \mathrm{m}^{2}$} \\
\hline $18.5-24.9$ & 1.00 & & 1.00 & & 1.00 & & 1.00 & \\
\hline $25.0-29.9$ & 0.96 & $(0.72,1.28)$ & 0.94 & $(0.71,1.23)$ & 0.52 & $(0.39,0.70)$ & 0.96 & $(0.71,1.31)$ \\
\hline$\geq 30.0$ & 0.82 & $(0.60,1.14)$ & 0.83 & $(0.60,1.13)$ & 0.45 & $(0.32,0.65)$ & 0.79 & $(0.63,0.98)$ \\
\hline \multicolumn{9}{|l|}{ Marital Status } \\
\hline Married/Common law & 1.00 & & 1.00 & & 1.00 & & 1.00 & \\
\hline Divorced, separated or widowed & 1.54 & $(1.06,2.26)$ & 1.63 & $(1.12,2.35)$ & 1.62 & $(1.08,2.43)$ & 1.51 & $(1.09,2.10)$ \\
\hline Single & 1.41 & $(0.84,2.36)$ & 1.50 & $(0.90,2.49)$ & 1.52 & $(0.87,2.66)$ & 1.52 & $(0.85,2.71)$ \\
\hline \multicolumn{9}{|l|}{ Educational attainment } \\
\hline Some high school & 1.00 & & 1.00 & & 1.00 & & 1.00 & \\
\hline High school diploma & 1.20 & $(0.73,1.95)$ & 1.06 & $(0.64,1.74)$ & 0.91 & $(0.52,1.61)$ & 1.00 & $(0.55,1.81)$ \\
\hline Technical school/College & 1.28 & $(0.81,2.02)$ & 1.10 & $(0.69,1.75)$ & 0.90 & $(0.53,1.53)$ & 0.93 & $(0.54,1.61)$ \\
\hline Some university/University degree & 1.40 & $(0.85,2.30)$ & 1.22 & $(0.74,2.01)$ & 1.03 & $(0.59,1.81)$ & 1.12 & $(0.62,2.01)$ \\
\hline Postorraduate university & 1.40 & $(0.78,2.53)$ & 1.08 & $(0.61,1.92)$ & 0.91 & $(0.48,1.71)$ & 0.97 & $(0.50,1.87)$ \\
\hline \multicolumn{9}{|l|}{ Employment status } \\
\hline Employed full-time & 1.00 & & 1.00 & & 1.00 & & 1.00 & \\
\hline Employed part-time & 1.19 & $(0.84,1.69)$ & 1.27 & $(0.90,1.78)$ & 1.19 & $(0.81,1.73)$ & 1.11 & $(0.74,1.67)$ \\
\hline Unemployed & 1.19 & $(0.81,1.75)$ & 1.27 & $(0.87,1.86)$ & 1.40 & $(0.92,2.13)$ & 1.41 & $(0.91,2.18)$ \\
\hline Retired & 2.30 & $(1.32,4.01)$ & 2.65 & $(1.56,4.48)$ & 3.04 & $(1.74,5.31)$ & 2.76 & $(1.57,4.87)$ \\
\hline Self-employed & 0.74 & $(0.21,2.62)$ & 0.76 & $(0.21,2.77)$ & 0.97 & $(0.22,4.19)$ & 1.20 & $(0.29,4.99)$ \\
\hline \multicolumn{9}{|l|}{ Annual household income } \\
\hline$<\$ 20,000$ & 1.00 & & 1.00 & & 1.00 & & 1.00 & \\
\hline$\$ 20,000-\$ 39,999$ & 1.16 & $(0.66,2.04)$ & 1.14 & $(0.64,2.04)$ & 1.06 & $(0.55,2.06)$ & 0.99 & $(0.49,1.98)$ \\
\hline$\$ 40,000-\$ 59,999$ & 1.26 & $(0.71,2.22)$ & 1.27 & $(0.71,2.26)$ & 1.16 & $(0.60,2.25)$ & 1.03 & $(0.51,2.06)$ \\
\hline$\$ 60,000-\$ 79,999$ & 1.62 & $(0.90,2.90)$ & 1.52 & $(0.84,2.75)$ & 1.39 & $(0.71,2.74)$ & 1.20 & $(0.59,2.43)$ \\
\hline$\$ 80,000-\$ 99,999$ & 1.80 & $(0.97,3.34)$ & 1.79 & $(1.17,2.75)$ & 1.58 & $(0.78,3.20)$ & 1.30 & $(0.62,2.73)$ \\
\hline$\geq \$ 100,000$ & 2.51 & $(1.36,4.63)$ & 2.43 & $(1.32,4.48)$ & 2.05 & $(1.03,4.08)$ & 1.56 & $(1.06,3.27)$ \\
\hline \multicolumn{9}{|l|}{ Self-rated health status } \\
\hline Excellent & 1.00 & & 1.00 & & 1.00 & & 1.00 & \\
\hline Very Good & 0.75 & $(0.52,1.08)$ & 0.72 & $(0.52,0.99)$ & 0.72 & $(0.53,0.97)$ & 0.67 & $(0.47,0.95)$ \\
\hline Good & 0.54 & $(0.37,0.80)$ & 0.52 & $(0.36,0.74)$ & 0.50 & $(0.34,0.73)$ & 0.47 & $(0.32,0.71)$ \\
\hline Fair or Poor & 0.38 & $(0.21,0.71)$ & 0.36 & $(0.19,0.67)$ & 0.37 & $(0.17,0.78)$ & 0.40 & $(0.19,0.85)$ \\
\hline \multicolumn{9}{|l|}{ Current smoking status } \\
\hline Non-smoker & 1.00 & & 1.00 & & 1.00 & & 1.00 & \\
\hline Occasional & 1.14 & $(0.58,2.23)$ & 1.17 & $(0.62,2.22)$ & 1.16 & $(0.58,2.31)$ & 1.13 & $(0.56,2.32)$ \\
\hline Daily & 0.65 & $(0.47,0.90)$ & 0.70 & $(0.50,0.97)$ & 0.77 & $(0.53,1.13)$ & 0.82 & $(0.55,1.22)$ \\
\hline Social Support ${ }^{f}$ & 1.12 & $(0.96,1.31)$ & 1.09 & $(0.94,1.28)$ & 1.08 & $(0.91,1.28)$ & 1.04 & $(0.87,1.25)$ \\
\hline
\end{tabular}

Abbreviations: ACS, American Cancer Society; AICR, American Institute for Cancer Research; CI, confidence interval; CSEP, Canadian Society for Exercise Physiology; OR, odds ratio; USDHHS, United States Department of Health and Human Services; PA, physical activity; WCRF, World Cancer Research Fund.

Note: Bolded values are significant.

${ }^{\mathrm{a}}$ Estimated from logistic regression using 10 -fold cross-validation.

${ }^{b}$ Minimum 2.5 hours/week of moderate to vigorous PA.

${ }^{c}$ Minimum 3.75 hours/ week of moderate to vigorous PA.

${ }^{\mathrm{d}}$ Minimum 5 hours/week of moderate to vigorous PA to prevent weight gain.

${ }^{\text {e }}$ Minimum 7 hours/week of moderate-intensity PA or 3.5 hours/week of vigorous PA.

${ }^{f}$ Using the Medical Outcomes Study Social Support Survey. ${ }^{30}$ 
to vigorous activity per week through large population-based surveys. Similarly, a recent study estimated that $15 \%$ of Canadian adults are active at these levels. ${ }^{66}$ However, because these estimates included participation in occupational, transportation and household activities in addition to leisure PA, it is difficult to compare them with our estimates, which considered only leisure PA. Total PA has been used to estimate PA prevalence estimates in the different jurisdictions, ${ }^{64,67-69}$ but a focus on leisure PA is valuable since this type of activity is most likely to be modifiable, unlike occupational and household activities. Established evidence suggests that risk for breast, colorectal, prostate and endometrial cancers is significantly reduced when higher intensity PA is undertaken. ${ }^{6,8,70}$ This is likely the result of a shift in inflammation biomarkers, insulin resistance, and sex and metabolic hormone levels that favour cancer risk reduction in response to moderate and vigorous leisure activities but not to light intensity household activities. ${ }^{12,71}$ Therefore, leisure PA is a logical target for population health interventions aimed at cancer prevention.

\section{Limitations of the study}

Our study had some limitations, including in interpreting the findings. Although fairly typical of random digit dialing (RDD) studies, the response rate was low, at less than $25 \%$, and the unweighted sample was not representative of the Alberta population. Despite trying to weight prevalence estimates to reflect more closely those of the Alberta population, the generalizability of our results may be limited. The data regarding PA were self-reported, which may result in over-reporting of activity levels due to social desirability bias. Measurement error and inaccurate estimates may have also come about because it can be difficult to recall $\mathrm{PA} ;{ }^{18}$ participants in our study were asked to remember exercise patterns from over a year-long period. However, the PYTPAQ has been shown to be valid and reliable in a large random sample of men and women. ${ }^{25}$ Our use of previously validated and reliability-tested instruments to measure PA and all other variables helped to minimize potential measurement error. ${ }^{25}$ In addition, the cross-sectional design of this study limits the interpretation of results to correlations and not as causal associations. Nonetheless, these results have identified factors that warrant further investigation as important intervention targets for increasing PA for cancer prevention in the population.

\section{Recommendations}

Given that $42 \%$ of Albertans are insufficiently active for general health benefits, future interventions should focus on encouraging sedentary individuals to exercise. These efforts should include the promotion of higher levels of PA to confer additional benefits for cancer prevention among this segment of the population as well as those who are already active. In 2005, Canadians spent approximately 6 hours each day on leisure activities, from watching television and surfing the internet, to participating in numerous hobbies, both sedentary and active. ${ }^{72}$ The availability of so many options for leisure time activities poses a challenge for physical activity promotion. It also highlights the need for effective interventions that strengthen those factors that facilitate physical activity and reduce any barriers to them.

Current national guidelines may not be sufficient for cancer prevention, nor for weight management. ${ }^{21}$ Given the ample evidence that obesity contributes to cancer risk, promoting sufficient levels of PA to support weight loss and management may be an important target for cancer prevention strategies in the population. Moreover, the specific dose of necessary $\mathrm{PA}$ is not clear, hence the variations in the guidelines. Guideline development depends on the evolving research linking PA to cancer, ${ }^{19-21}$ which has consisted mainly of observational studies of varying designs. ${ }^{73}$ Randomized trials are needed to make definitive dose recommendations, and until these exist, it may be prudent to provide a graded set of guidelines that highlight the health benefits associated with various levels and intensities of PA, including those levels that will lead to a greater cancer risk reduction. ${ }^{74}$ Lastly, further research is needed to develop effective interventions to promote PA that include individual-level motivational factors as well as social and environmental facilitators of PA.

\section{Acknowledgments}

This project was funded by the Alberta Cancer Foundation. Fabiola Aparicio-Ting was supported by a Doctoral Studentship from the Canadian Cancer Society. Christine Friedenreich was supported by a Health Senior Scholar Award from the Alberta Heritage Foundation for Medical Research. Ronald Plotnikoff was supported by an Applied Public Health Chair from the Canadian Institutes of Health Research. The authors gratefully acknowledge Paula Robson, Principal Investigator for the Tomorrow Project, for sharing baseline data from this cohort. Thanks also to Heather Whelan and Will Rosner for their assistance in accessing and using the Tomorrow Project dataset.

\section{References}

1. Canadian Cancer Society's Steering Committee. Canadian Cancer Statistics 2011: featuring colorectal: featuring coloectal cancer. Toronto (ON): Canadian Cancer Society; 2011.

2. National Cancer Institute of Canada. Canadian Cancer Statistics 2004. Toronto (ON): National Cancer Institute of Canada; 2004.

3. Colditz GA, Sellers TA, Trapido E. Epidemiology - identifying the causes and preventability of cancer? Nat Rev Cancer. 2006;6(1):75-83.

4. Stein CJ, Colditz GA. Modifiable risk factors for cancer. Brit J Cancer. 2004;90(2):299-303.

5. Courneya KS, Friedenreich CM, editors. Physical activity and cancer. Berlin (DE): Springer; 2011.

6. Wolin KY, Yan Y, Colditz GA, Lee IM. Physical activity and colon cancer prevention: a meta-analysis. Br J Cancer. 2009;100(4):611-6. 
7. Cust AE. Physical activity and gynecologic cancer prevention. In: Courneya KS, Friedenreich CM, editors. Physical activity and cancer. New York (NY): Springer; 2011. p. $159-88$.

8. Monninkhof EM, Elias SG, Vlems FA, van der Tweel I, Schuit AJ, Voskuil DW, et al. Physical activity and breast cancer: a systematic review. Epidemiology. 2007;18(1):137-57.

9. Leitzmann MF. Physical activity and genitourinary cancer prevention. In: Courneya KS, Friedenreich CM, editors. Physical activity and cancer. New York (NY): Springer; 2011. p. 43-72.

10. Rogers CJ, Colbert LH, Greiner JW, Perkins SN, Hursting SD. Physical activity and cancer prevention: pathways and targets for intervention. Sports Med. 2008;38(4):271-96.

11. Neilson HK, Friedenreich CM, Brockton NT, Millikan RC. Physical activity and postmenopausal breast cancer: proposed biologic mechanisms and areas for future research. Cancer Epidemiol Biomarkers Prev. 2009;18(1):11-27.

12. McTiernan A. Mechanisms linking physical activity with cancer. Nat Rev Cancer. 2008;8(3):205-11.

13. Renehan AG, Soerjomataram I, Leitzmann MF. Interpreting the epidemiological evidence linking obesity and cancer: a framework for population-attributable risk estimations in Europe. Eur J Cancer. 2010;46(14):2581-92.

14. Wolin KY, Carson K, Colditz GA. Obesity and cancer. Oncologist. 2010;15(6):556-65.

15. Sharratt MT, Hearst WE. Canada's physical activity guides: background, process, and development. Can J Public Health. 2007;98(2):S9-15.

16. Canadian Society for Exercise Physiology. Canadian physical activity guidelines for adults 18-64 years [Internet]. Ottawa (ON): CSEP; 2003 [cited 2003 Oct 14]. Available from: http://www.csep.ca/CMFiles /Guidelines/CSEP-InfoSheets-adults-ENG.pdf

17. Sallis JF, Owen N. Physical activity and behavioral medicine. Thousand Oaks (CA): SAGE Publications, Inc.; 1999. Chapter 5, Measuring physical activity; p. 71-91.
18. Pettee KK, Storti KL, Ainsworth BE, Kriska AM. Measurement of physical activity and inactivity in epidemiological studies. In: Lee IM, editor. Epidemiologic methods in physical acitivity studies. New York (NY): Oxford University Press; 2009. p. 15-33.

19. Byers T, Nestle M, McTiernan A, Doyle C, Currie-Williams A, Gansler T, et al. American Cancer Society guidelines on nutrition and physical activity for cancer prevention: reducing the risk of cancer with healthy food choices and physical activity. CA Cancer J Clin. 2002;52(2):92-119.

20. U.S. Department of Health and Human Services and U.S. Department of Agriculture. Dietary guidelines for Americans, 2005. Washington (DC): U.S. Department of Health and Human Services; 2005. Joint publication of the U.S. Department of Agriculture; 2005.

21. World Cancer Research Fund and the American Institute for Cancer Research. Food, nutrition, physical activity and the prevention of cancer: a global perspective. Washington (DC): American Institute for Cancer Research; 2007.

22. Bryant H, Robson PJ, Ullman R, Friedenreich C, Dawe U. Population-based cohort development in Alberta, Canada: a feasibility study. Chronic Dis Can. 2006;27(2):51-9.

23. Lavrakas PJ. Telephone survey methods sampling, selection, and supervision. 2nd ed. Thousand Oaks (CA): SAGE Publications; 1993. Chapter 2, Random Digit Dialing; p. 33-48.

24. Statistics Canada. Residential Telephone Service Survey (RTSS). Ottawa (ON): Statistics Canada; 2001.

25. Friedenreich CM, Courneya KS, Neilson HK, Matthews CE, Willis G, Irwin M, et al. Reliability and validity of the Past Year Total Physical Activity Questionnaire. Am J Epidemiol. 2006;163:959-70.

26. Statistics Canada. Canadian Community Health Survey (CCHS): Cycle 1.1: extending the wealth of health data in Canada. Available from: http://www.statcan.ca / english / concepts/health-sante /cchs-escc-info.htm
27. National Cancer Institute. A 16-year randomized screening study for prostate, lung, colorectal and ovarian cancer - PLCO Trial [Internet]. Bethesda (MD): National Cancer Institute; 1993 [cited 2010 Mar 4]; Available from: http://www.cancer.gov /clinicaltrials/PLCO-1

28. International Agency for Research on Cancer. EPIC Project [Internet]. Lyon (FR): World Health Organization; 2010 [cited 2010 Mar 4]. Available from: http://epic.iarc.fr /about.php

29. Ainsworth BE, Haskell WL, Whitt MC, Irwin ML, Swartz AM, Strath SJ, et al. Compendium of physical activities: an update of activity codes and MET intensities. Med Sci Sports Exerc. 2000;32 (9 Suppl):S498-504.

30. Sherbourne CD, Stewart AL. The MOS social support survey. Soc Sci Med. 1991;32(6):705-14.

31. Statistics Canada. 2001 Census of Canda. Ottawa (ON): Statistics Canada; 2003 [cited 2010 Mar 4]. Available from: http://www12.statcan.ca/english /census01/home/index.cfm

32. Statistics Canada. Canadian Community Health Survey 2003: User Guide for the Public Use Microdata File. Ottawa (ON): Statistics Canada; 2005 [cited 2010 Mar 4]. Available from: http://www.statcan.gc.ca/dli-ild/meta /cchs-escc/cycle2-1/guide-eng.pdf

33. Norman GR, Streiner DL. Biostatistics: the bare essentials. $2^{\text {nd }}$ ed. Hamilton $(\mathrm{ON})$ : BC Decker; 2000. Chapter 14, Multiple regression; p. 127-38.

34. Kleinbaum DG, Klein M. Logistic regression: a self-learning text. 2nd ed. New York (NY): Springer; 2002. Chapter 6, Modeling strategy guidelines; p. 161-90.

35. Harrell FE. Regression modeling strategies. New York (NY): Springer; 2001. Chapter 5, Resampling, validating, describing, and simplifying the model; p. 87-104.

36. Harrell FE. Regression modeling strategies. New York (NY): Springer; 2001. Chapter 10, Binary logistic regression; p. 215-68.

37. StataCorp LP. STATA Release 10.0. College Station (TX): Stata Corporation; 2001. 
38. Janz NK, Champion VL, Strecher VJ. The health belief model. In: Glanz K, Rimer BK, Lewis FM, editors. Health behavior and health education: Theory, research and practice. 3rd ed. San Francisco (CA): Jossey-Bass; 2001. p. 45-66.

39. Loitz C, Berry TR, Spence JC. 2009 Alberta survey on physical activity: a concise report. Edmonton (AB): Alberta Centre for Active Living; 2009.

40. Trost SG, Owen N, Bauman AE, Sallis JF, Brown W. Correlates of adults' participation in physical activity: review and update. Med Sci Sports Exerc. 2002;34(12):1996-2001.

41. Seefeldt V, Malina RM, Clark MA. Factors affecting levels of physical activity in adults. Sports Med. 2002;32(3):143-68.

42. Ross CE. Walking, exercising, and smoking: Does neighborhood matter? Soc Sci Med. 2000;51(2):265-74.

43. Azevedo MR, Araujo C, Reichert FF, Siqueira FV, da Silva MC, Hallal PC. Gender differences in leisure-time physical activity. Int J Public Health. 2007;52(1):8-15.

44. Barrett JE, Plotnikoff RC, Courneya KS, Raine KD. Physical activity and type 2 diabetes: exploring the role of gender and income. Diabetes Educ. 2007;33(1):128-43.

45. Parsons EM, Betz NE. The relationship of participation in sports and physical activity to body objectification, instrumentality, and locus of control among young women. Psychol Women Q. 2001;25(3):209-22.

46. Stutts WC. Physical activity determinants in adults: perceived benefits, barriers, and self efficacy. AAOHN J. 2002;50(11):499-507.

47. McDermott L. A qualitative assessment of the significance of body perception to women's physical activity experiences: revisiting discussions of physicalities. Sociol Sport J. 2000;17(4):331-63.

48. Thompson AM, Humbert M, Mirwald RL. A longitudinal study of the impact of childhood and adolescent physical activity experiences on adult physical activity perceptions and behaviors. Qual Health Res. 2003;13(3):358-77.
49. Levine JA, McCrady SK, LanninghamFoster LM, Kane PH, Foster RC, Manohar $\mathrm{CU}$. The role of free-living daily walking in human weight gain and obesity. Diabetes. 2008;57(3):548-54.

50. Dishman RK, Sallis JF. Physical activity, fitness, and health: International proceedings and consensus statement. Bouchard C, Shephard RJ, Stephens $\mathrm{T}$ (editors). Champaign (IL):Human Kinetics Publishers; 1994. Chapter 3, Determinants and interventions for physical activity and exercise; p. 214-38.

51. Godin G, Belanger-Gravel A, Nolin B. Mechanism by which BMI influences leisure-time physical activity behavior. Obesity. 2008;16(6):1314-7.

52. Fox KR, Hillsdon M. Physical activity and obesity. Obes Rev. 2007;1:115-21.

53. Lau DC, Douketis JD, Morrison KM, Hramiak IM, Sharma AM, Ur E, et al. 2006 Canadian clinical practice guidelines on the management and prevention of obesity in adults and children. CMAJ. 2007;176(8):117.

54. Physical Activity Advisory Committee. Physical Activity Guidelines Advisory Committee report, 2008. Washington (DC): U.S. Department of Health and Human Services; 2008.

55. Bensimhon DR, Kraus WE, Donahue MP. Obesity and physical activity: a review. Am Heart J. 2006;151(3):598-603.

56. Mortensen LH, Siegler IC, Barefoot JC, Gronbaek M, Sorensen TIA. Prospective associations between sedentary lifestyle and BMI in midlife. Obesity. 2006;14(8):1462-71.

57. Petersen L, Schnohr P, Sorensen TIA Longitudinal study of the long-term relation between physical activity and obesity in adults. Int $\mathrm{J}$ Obes Relat Metab Disord. 2003;28(1):105-12.

58. Giles-Corti B, Donovan RJ. Socioeconomic status differences in recreational physical activity levels and real and perceived access to a supportive physical environment. Prev Med. 2002;35(6):601-11.
59. Booth ML, Macaskill P, Owen N, Oldenburg B, Marcus BH, Bauman A. Population prevalence and correlates of stages of change in physical activity. Health Educ Q. 1993;20(3):431-40.

60. Statistics Canada. Health indicator profile, annual estimates, by age group and sex, Canada, provinces, territories, health regions (2007 boundaries) and peer groups, occasional. Table 105-0501 (All Canada) [Internet]. Ottawa (ON): CANSIM (database); 2007 [cited 2011 Feb 18]. Available from: http://www5.statcan.gc.ca /cansim/a01?lang = eng

61. Statistics Canada. Health indicator profile, annual estimates, by age group and sex, Canada, provinces, terrotories, health regions (2007 boundaries) and peer groups, occasional. Table 105-0501 (Alberta) [Internet]. Ottawa (ON): CANSIM database; 2007 [cited 2009 Mar 18]. Available from: http://cansim2.statcan.gc.ca /cgi-win/cnsmcgi.exe?Lang = E\&CNSM-Fi =CII/CII_1-eng.htm

62. Statistics Canada. Canadian Community Health Survey, cycle 2.1 questionnaire. 2003 [cited 2009 January 17]. Available from: http://www.statcan.gc.ca/concepts /health-sante/cycle2_1/quest-eng.htm

63. Pereira MA, FitzerGerald SJ, Gregg EW, Joswiak ML, Ryan WJ, Suminski RR, et al. A collection of Physical Activity Questionnaires for health-related research. Med Sci Sports Exerc. 1997;29(6 Suppl):S1-205.

64. Centers for Disease Control and Prevention. Adult participation in recommended levels of physical activity--United States, 2001 and 2003. MMWR. 2005;54(47):1208-12.

65. Sjostrom M, Oja P, Hagstromer M, Smith BJ, Bauman A. Health-enhancing physical activity across European Union countries: the Eurobarometer study. J Public Health. 2006;14(5):291-300.

66. Colley RC, Garriguet D, Janssen I, Craig CL, Clarke J, Tremblay MS. Physical activity of Canadian adults: accelerometer results from the 2007 to 2009 Canadian Health Measures Survey. Health Rep. 2011;22(1):15-23. 
67. Rutten A, Abu-Omar K. Prevalence of physical activity in the European Union. Soz.-Praventivmed. 2004;49(4):281-9.

68. Rutten A, Ziemainz H, Schena F, Stahl T, Stiggelbout M, Auweele YV, et al. Using different physical activity measurements in eight European countries. Results of the European Physical Activity Surveillance System (EUPASS) time series survey. Public Health Nutr. 2003;6(4):371-6.

69. Bauman A, Ainsworth BE, Bull F, Craig CL, Hagstromer M, Sallis JF, et al. Progress and pitfalls in the use of the International Physical Activity Questionnaire (IPAQ) for adult physical activity surveillance. J Phys Act Health. 2009;6(1).

70. Friedenreich CM, Cust AE. Physical activity and breast cancer risk: impact of timing, type and dose of activity and population subgroup effects. Brit J Sports Med. 2008;42(8):636-47.

71. Autenrieth C, Schneider A, Doring A, Meisinger C, Herder C, Koenig W, et al. Association between different domains of physical activity and markers of inflammation. Med Sci Sports Exerc. 2009;41(9):1706-13.

72. Ifedi F. Sport participation in Canada, 2005. Ottawa (ON): Statistics Canada; 2008. Available from: http://publications.gc.ca /collections/collection_2008/statcan /81-595-M/81-595-MIE2008060.pdf

73. Friedenreich CM, Neilson HK, Lynch BM. State of the epidemiological evidence on physical activity and cancer prevention. Eur J Cancer. 2010;46(14):2593-604.

74. Cerin E, Leslie E, Bauman A, Owen N. Levels of physical activity for colon cancer prevention compared with generic public health recommendations: population prevalence and sociodemographic correlates. Cancer Epidemiol Biomarkers Prev. 2005;14(4):1000-2. 